\title{
AS RELAÇÕES CTSA NA LICENCIATURA EM QUÍMICA: UMA PROPOSTA DE RECURSO DIDÁTICO VOLTADO AO SERTÃO NORDESTINO
}

\author{
Albino Oliveira Nunes ${ }^{1}$, Josivânia Marisa Dantas ${ }^{2}$, Luiz Di Souza ${ }^{3}$ \\ Instituto Federal do Rio Grande do Norte - Campus Mossoró \\ Rua Raimundo Firmino de Oliveira, 400 - Conj. Ulrick Graff - Mossoró-RN CEP: 59.628-330
}

\section{RESUMO}

O presente artigo descreve a elaboração de recurso didático sobre as relações CTSA voltada ao curso de licenciatura em química ofertado pela Universidade do Estado do Rio Grande do Norte (UERN). O referido material compõe uma unidade didática estruturada em $12 \mathrm{~h} / \mathrm{a}$ e direcionada a disciplina instrumentação para o ensino da química. Aqui relatamos a elaboração do recurso didático que deu suporte à referida unidade. O mesmo encontra-se estruturado em três unidades, nas quais foram abordados respectivamente: aspectos epistemológicos das ciências naturais; $\mathrm{O}$ movimento CTSA e o ensino de ciências e, por fim, apresentado um tema local para o ensino de química dentro de uma perspectiva CTSA: O Rio Apodi - Mossoró.

Palavras-chave: CTSA, educação química, formação inicial de professores.

\section{ABSTRACT}

The present article describes the development of educational materials about STSE relationship focused on the chemistry degree course offered by the University of Rio Grande do Norte State (UERN). The material comprises a structured unit in 12 hours and directed to the discipline of Instrumentation for the teaching of chemistry. Here we report the elaboration of teaching materials that have given support to the unit. The material is structured into three units, in which we respectively dealt with: Epistemological Aspects of Natural Sciences, The STSE movement and science teaching, and finally we present a local theme for the teaching of chemistry in a STSE perspective: the apodi - Mossoró river.

Keywords: STSE, chemistry education, initial education of teacher.

\footnotetext{
1 professor de química, Mestre em Ensino de Ciências, Instituto Federal do Rio Grande do Norte, Campus Mossoró. E-mail: albino.nunes@ifrn.edu.br

2 professor de química, Doutora em Ciências, Universidade Federal do Rio Grande do Norte, Centro de Educação. Campus Universitário - Av. Senador Salgado Filho, 3000. Lagoa Nova. CEP: 59072-970 - Natal, RN - Brasil. E-mail: josivaniamd@yahoo.com.br

3 professor de química, Doutor em Química. Universidade do Estado do Rio Grande do Norte, Fanat, Departamento de Química. BR. 110, Km 46, Laboratório de Ensaios Físico-Químicos. CEP 59600-000 - Mossoró, RN - Brasil. E-mail: luizsouza@uern.br
} 


\section{Ensino de Ciências e Matemática Recurso didático de Química voltado ao Sertão Nordestino}

\section{INTRODUÇÃO}

O movimento Ciência-Tecnologia-Sociedade (CTS) ou em inglês (STS) surgiu nos Estados Unidos da América, na educação universitária, entre as décadas de 60 e 70. Esse momento histórico ficou marcado pela efervescência de diversos estudos em áreas limites entre o trinômio CTS, como a existência de duas culturas discutida por C.P. Snow e os limites do crescimento denunciados por Dennis Meadows. Enquanto um campo de estudo a sigla CTS designa tendências diferentes no estudo social da ciência e da tecnologia, surgidas como resposta à relação desequilibrada que a sociedade mantinha com a ciência e a tecnologia (MEMBIELA, 2001; CEREZO, 1998). Alguns autores como Sutil (2008) situam no pós Segunda Guerra e na descrença gerada com os efeitos danosos da ciência e tecnologia, o surgimento do campo de estudo designado como CTS. 0 que passou a ser questionado naquele momento histórico foi a pretensa relação linear existente entre Ciência e Tecnologia (CT) e a sociedade. Segundo essa perspectiva o desenvolvimento do binômio CT significaria invariavelmente um avanço do bem-estar social.

Ainda sobre a história do CTS, García, López Cerezo \& Luján (1996) destacam dentro do movimento tradições de pesquisa que foram designadas pela mesma sigla: STS, do inglês 1) Science and Tecnology Studies (tradição Européia) e 2) Science, Tecnology and Society, (tradição americana). A primeira voltou-se ao estudo da influência social e dos antecedentes históricos na construção dos conhecimentos cientifico-tecnológicos. Iniciada nas universidades européias, essa linha está fortemente embasada na sociologia da ciência e na teoria kuhniana sobre as revoluções científicas, e por isso caracteriza-se como uma linha educativa. (CEREZO, 1998).

A segunda objetivou prioritariamente estudos sobre o impacto da ciência e da tecnologia sobre a sociedade e o ambiente. Podemos atribuir à tradição americana uma preocupação pragmática em oposição à tradição Européia que ressaltou aspectos históricos. Suas bases encontram-se principalmente na filosofia e teoria política, tendo a consolidação dos seus estudos se dado fortemente pelo ensino e reflexão política (CEREZO, 1998).

Como ainda destaca esse autor cada uma dessas tradições tem criado seus próprios eventos científicos, revistas especializadas, associações e manuais. Mesmo assim, tendo-se em vista as discordâncias entre as tradições pode-se indicar algum consenso: 
1- Rechaço à imagem da ciência como atividade pura;

2- Crítica à concepção de tecnologia, como ciência aplicada;

3- Crítica ao modelo tecnocrático.

O que foi discutido acima pode ser exemplificado na Figura 1 abaixo extraída de García, López Cerezo e Luján Lopez (1996):

Figura 1. Tradições de pesquisa CTSA.

\section{FATORES SOCIAIS ANTECEDENTES $\longrightarrow$ Ciência e Tecnologia $\longrightarrow$ Consequências Sociais}

\section{Tradição Européia}

Tradição Americana

Fonte: Cerezo e Luján Lopez (1996).

Podemos destacar, ainda, sobre o surgimento desse novo campo de estudos, o fato de que este tem suas raízes na reação social e acadêmica frente à visão positivista até então hegemônica (García, López Cerezo \& Luján Lopez, 1996). Os fatores que confluíram para este surgimento foram as discussões acadêmicas frente ao absolutismo epistemológico, tais como:

- A discussão sobre o problema da indução (ou problema de Hume);

- A incomensurabilidade entre teorias científicas concorrentes;

- As discussões levantadas por Thomas Kuhn em seu livro A estrutura das revoluções científicas, sobre a sociologia da ciência, a importância do paradigma para a construção de períodos de ciência normal, a natureza da ciência revolucionária onde diversas teorias concorrentes competiriam para tomar parte em um novo paradigma e o papel da comunidade científica;

- As discussões sobre a impossibilidade de uma observação neutra, uma vez que toda observação traria um carga teórica que lhe precede.

Outra razão que se pode elencar é a mudança das percepções sobre a tecnologia em função da produção de material bélico e os efeitos ambientais do uso de produtos tecnológicos, exemplificado pela denuncia feita por Rachel Carson em seu livro "A primavera silenciosa" 
(MEMBIELA, 2001). Essa mudança é considerada como motivadora de uma reação social à hegemonia do conhecimento técnico-científico que se expressou de diversas formas:

- Uma reação social dentro da academia representada pela ação de grupos de cientistas de esquerda como o Science for people que denunciavam os abusos cometidos e justificados com o conhecimento científico-tecnológico;

- Os grupos defensores de tecnologias alternativas, ou tecnologias brandas que não afetassem significativamente o ambiente ou estruturas sociais;

- A ação governamental frente a reação social, como a criação do EPA (Environmental Protection Agency);

- E principalmente o ativismo social dos mais diversos grupos, mas entre os quais podemos destacar, ambientalistas, feministas e grupos pacifistas.

É interessante notar que García, López Cerezo e Luján Lopez (1996) apontam para a consolidação do movimento em paralelo com a consolidação do ativismo social referente às causas sociais e tecnológicas, o que reforça a idéia de que a cidadania tem um papel fundamental na gestão dos produtos e artefatos tecnológicos. No tocante à consolidação do movimento Cerezo (1998) sumariza três grandes direções tomadas pelos estudos CTS desde sua origem:

- No campo de investigação, os estudos CTS tem proporcionado uma reflexão contextualizada para a construção do conhecimento científico enquanto um processo social;

- No campo político tem defendido o controle social da ciência e da tecnologia e a criação de mecanismos democráticos desse controle.

- Na educação, tem impulsionado o aparecimento de inúmeras propostas e recursos didáticos que visem discutir a ciência e a tecnologia como processos sociais.

Mediante a discussão do movimento CTS, mais recentemente tem-se defendido a sigla CTSA, como forma de dar maior destaque às questões ambientais dentro da discussão sobre CT. Segundo Tomazello (2009) a letra "A" foi incorporada à sigla tradicional CTS, quando da transposição do campo de estudo para o ensino de ciências. Ainda que não haja consenso 
sobre a sigla mais adequada e havendo inúmeras propostas (CTA - Ciência, Tecnologia e Ambiente, CTCA - Ciência, Tecnologia, Cultura e Ambiente, CTSAE - Ciência, Tecnologia, Sociedade, Ambiente e Educação) adotaremos a sigla CTSA que traduz a importância que o ambiente têm nas relações sócio-cientifico-tecnológicas. A Figura 2 representa as relações estabelecidas pelo sistema CTSA.

Figura 2. Representação das Relações CTSA.

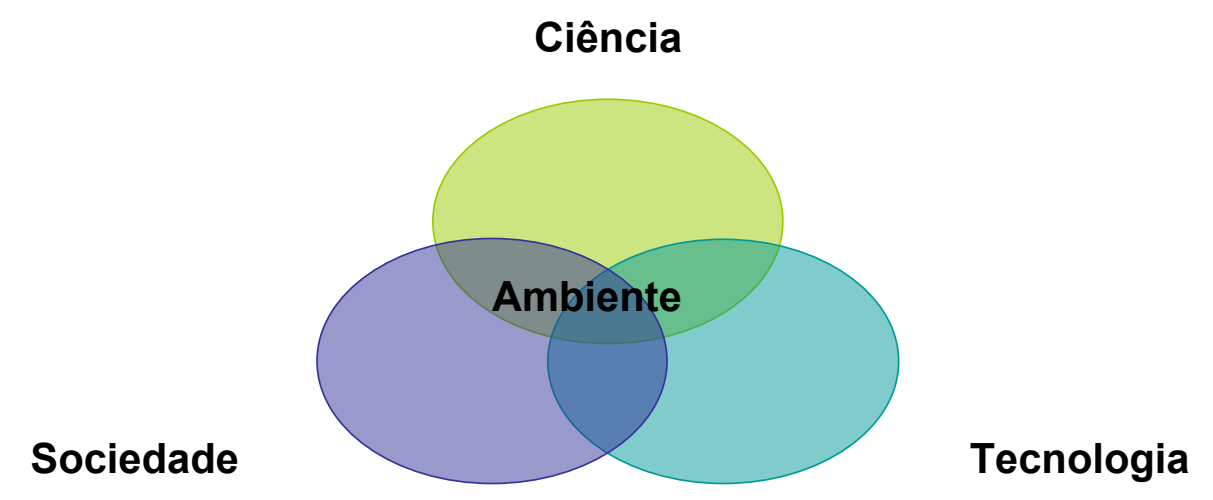

Fonte: Tomazello (2009).

A partir dessa perspectiva teórica é que elaboramos uma unidade didática para trabalhar as relações CTSA para a licenciatura em química. A referida unidade foi projetada a partir da realidade local da cidade de Mossoró que faz parte da bacia hidrográfica do Rio ApodiMossoró e conta com o curso de licenciatura em química. Neste artigo relatamos a elaboração do material de apoio produzido como subsídio a unidade didática.

\section{O CONTEXTO DO PROJETO}

\section{A cidade}

A cidade de Mossoró é a segunda maior do Rio Grande do Norte, com 234.390 habitantes tem sua economia baseada na agricultura, comércio, turismo de eventos e na exploração de sal marinho e petróleo (IBGE, 2009). Sendo esta última apontada como uma das razões pelas quais a cidade passa por um acentuado crescimento demográfico. A cidade é banhada pelo Rio 
Apodi-Mossoró, que se encontra poluído e onde nota-se o processo de eutrofização proveniente do despejo de matéria orgânica no manancial.

No tocante à escolaridade básica, a cidade possui diversas escolas públicas e privadas de ensino fundamental e médio, além de um Instituto Federal que oferece educação média, tecnológica e superior. Além da referida Universidade onde foi realizada a pesquisa, ofertam cursos superiores no município a Universidade Federal Rural do Semi-Árido - UFERSA, a Universidade Potiguar (UNP), Faculdade Mater Christi e a Faculdade de Enfermagem e Medicina Nova Esperança (FACENE).

\section{A universidade}

A Universidade do Estado do Rio Grande do Norte (UERN) é uma instituição de Ensino Superior com grande inserção em todo o estado e possuindo Campi instalados nas cidades de Mossoró (Central), Patu, Assu, Pau dos Ferros e Natal, bem como núcleos em Caraúbas, Areia Branca, Apodi, Macau, João Câmara, São Miguel, Alexandria, Umarizal, Touros, Caicó e Nova Cruz. São oferecidos um total de 24 (vinte e quatro) cursos de graduação entre os quais as licenciaturas de biologia, matemática, física e química. Esta Universidade em sua formação tem como marco histórico a criação da FACEM (Faculdade de Ciências Econômicas de Mossoró) no ano de 1943, apoiada pela então União Caixeiral, entidade que também mantinha na cidade a Escola Técnica de comércio União Caixeiral.

Somente no ano de 1968, o decreto estadual no 5.025 autoriza o funcionamento da Universidade Regional do Rio Grande do Norte (URRN), que contava à época com as Faculdades de Ciências Econômicas, Faculdade de Serviço Social, Faculdade de Filosofia, Ciências e Letras e a Escola Superior de Enfermagem. Em 1987, a Universidade foi estadualizada pelo então governador Radir Pereira, e somente em 1993 através da portaria ministerial no874 foi reconhecida pelo Conselho Federal de Educação. Finalmente no ano de 1997, sua denominação foi mudada de Universidade Regional do Rio Grande do Norte - URRN para Universidade do Estado do Rio Grande do Norte - UERN, nome que atualmente possui (UERN, 2009). 


\section{O curso de química}

O curso de licenciatura em química da UERN foi criado no ano de 1993, através da resolução no 07/93 - CONSUNI, juntamente com as licenciaturas de biologia, física e matemática (DQUERN, 2008). A implantação dos referidos cursos provém da transformação do curso de licenciatura plena em ciências. O curso de química teve como coordenadores de sua implantação os professores Francisco Arnaldo Viana e Isauro Beltran Nuñez, sendo reconhecido pelo Ministério da Educação no ano de 1996.

Administrativamente os cursos de biologia, física e química eram vinculados Departamento de Ciências Naturais (DCN), contudo a dificuldade de gerir os três cursos promoveu a criação dos departamentos de Ciências Biológicas (DCB), Departamento de Física (DF) e o Departamento de Química (DQ), aprovados pelo CONSEPE em 1997, mas só implantados em 2000. Quanto à sua estrutura didática o curso de química contou com um fluxo curricular entre os anos de 1993 a 1999. Em 1999 foi elaborado o primeiro projeto político pedagógico (PPP), projeto este que passou por reformulações em 2002. A partir de 2004 o Departamento de Química iniciou novas discussões para a elaboração de um novo PPP, que contemplasse as exigências do MEC, e que fosse adequado para a formação dos profissionais pretendidos. Este veio a ser aprovado em 2008. O Departamento de Química conta hoje com 13 professores permanentes e 6 professores temporários. Sendo oferecidas anualmente 30 vagas para o ingresso de alunos somente para a modalidade licenciatura.

\section{A ELABORAÇÃo DO RECURSO DIDÁTICO}

A elaboração do recurso didático foi realizada com base em três eixos principais:

I. Revisão bibliográfica sobre as concepções, atitudes, crenças e visões de professores em formação e professores em exercício;

II. Levantamento das atitudes e crenças dos licenciandos pesquisados sobre as relações CTSA;

III. Consulta ao livro "Química e Sociedade", tendo em vista que este apresenta um enfoque CTS para o ensino-aprendizagem em química e que é um dos livros aprovados no último Programa Nacional do livro didático do Ensino Médio (PNLEM). 
Para cumprir tais objetivos foram elaborados três módulos de ensino contendo respectivamente elementos de epistemologia da ciência, discussão das relações CTSA e uma unidade didática para o contexto local. A estrutura geral do material pode ser observada abaixo:

- Módulo 1: questionando a hegemonia do conhecimento técnico-científico;

- Módulo 2: as relações entre a ciência, a tecnologia, o ambiente e a sociedade - movimento CTSA;

- Módulo 3: proposta temática para a educação química em uma perspectiva CTSA: o rio Mossoró.

\section{Primeiro e segundo módulos}

Segundo Manassero Mas e Vazquez Alonso (2001) muitos professores e estudantes teriam crenças e atitudes em relação à Ciência e à Tecnologia que seriam denominadas ingênuas ou inadequadas das quais se podem destacar:

- O mito da verdade absoluta;

- O realismo ingênuo;

- A negação de influência de fatores sociais sobre a ciência;

Em trabalhos anteriores Nunes e Dantas (2012), Nunes et al (2013) analisaram as atitudes e crenças dos estudantes de química no estado do Rio Grande do Norte e as atitudes e crenças dos estudantes da rede federal de educação tecnológica concluindo em ambos os trabalhos que estes apresentam em grande medida estas crenças. Sendo assim, o primeiro módulo de ensino foi proposto para discutir elementos de epistemologia da ciência que diretamente se relacionam com o enfoque CTSA. Essa proposta também se apoiou no fato de que a estrutura curricular da licenciatura em Química da Universidade do Estado do Rio Grande do Norte, apenas contempla "Introdução à Filosofia da Ciência", enquanto uma disciplina eletiva, e que alguns conceitos de Filosofia são necessários ao entendimento de algumas questões dentro da discussão do sistema de interações CTSA. Desta forma, o primeiro módulo buscou fazer uma brevíssima síntese de idéias contidas nas epistemologias positivistas, poperiana, kunhiana e de Paul Feyrebend, dando destaque às críticas feitas ao modelo positivista de entendimento da ciência. 
A construção do segundo módulo foi motivada pela intencionalidade de discutir cada componente do sistema CTSA. Tendo em vista a percepção de algumas crenças apresentadas pelos estudantes pesquisados: a) A perspectiva salvacionista; b) 0 não entendimento da relação entre Ciência e Tecnologia; c) A aceitação do modelo tecnocrático de decisão.

Neste módulo foi apresentado o histórico e contribuições do Movimento CTSA para o ensino de ciências, bem como foram discutidos aspectos sobre a natureza da ciência, a natureza da técnica e tecnologia, questões sobre a sociedade contemporânea, e a interação entre os componentes do trinômio CTS com o ambiente. Para a inserção dos tópicos relacionados, e ao longo da discussão, foram utilizados elementos lúdicos, tais como ilustrações, charges, poemas e letras de canções populares. A intenção de inserir esses elementos lúdicos era proporcionar um momento de reflexão prévia ao estudo teórico de cada um dos tópicos relacionados. O que podemos exemplificar com o trecho da canção "Partido Clementina de Jesus":

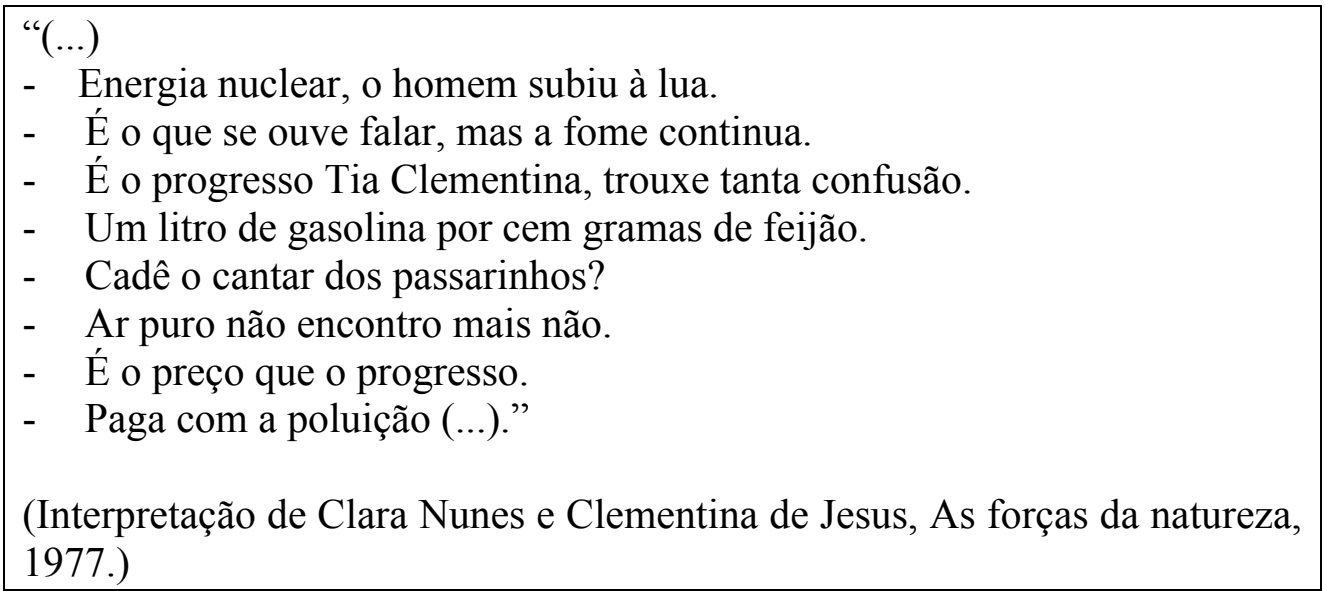

0 trecho acima reproduzido foi utilizado para promover uma discussão inicial que precedeu à leitura do histórico do movimento CTSA e às discussões e reflexões próprias sobre a não linearidade do desenvolvimento científico e tecnológico e suas relações com o bem estar socioambiental.

\section{Considerações sobre o terceiro módulo}

O terceiro módulo foi elaborado com base na realidade local da degradação do Rio ApodiMossoró. Este rio passa por três importantes cidades do interior do estado do Rio Grande do 


\section{Ensino de Ciências e Matemática \\ Recurso didático de Química voltado ao Sertão Nordestino}

Norte que atualmente contam com cursos de licenciatura em química: Mossoró, Apodi, e Pau dos Ferros. Na primeira destas cidades onde está localizado o Campus Central da UERN o rio sofre uma tricotomização e divide a cidade. A seguir são descritos os passos da elaboração deste material.

\section{Contexto do Rio Mossoró}

A primeira etapa para a elaboração deste capítulo constituiu-se na análise documental de livros, artigos, e trabalhos científicos que tratam direta ou indiretamente da bacia do Rio Apodi-Mossoró. Descrevemos a seguir os dados históricos e resultados de pesquisas que corroboram a idéia de que a bacia do rio constitui-se um tema adequado para discutir as relações CTSA naquela região. A cidade de Mossoró é banhada pela Bacia hidrográfica do Rio Apodi-Mossoró e suas histórias podem ser confundidas como salientam Cascudo (1996) e Câmara et al (2007). Segundo Cascudo(1996) o nome do Rio e da cidade provêm de uma tribo dos Cariris chamada Mouxorós ou Monxorós, "os quais faziam uso de suas águas e da mata ciliar para a caça, pesca e coleta de raízes e frutos". Essa tribo vivia às margens do rio resistindo à dominação portuguesa das terras e assaltando gado, sendo sua procedência desconhecida, sabendo-se apenas que foi expulsa para a região de São José do Mipibu, onde se dispersou etnicamente. Ainda em outro momento Cascudo(1996) comenta sobre a importância do Rio para a cidade:

\footnotetext{
"A água fixa o homem. Em Mossoró há uma batalha de duzentos anos para fixar a água. Era uma região conquistada por gado, mas a própria pecuária determinaria o aspecto disperso e fragmentário do povoamento. Mas a população se adensou nos pontos ásperos onde ainda hoje é uma surpresa a cidade ter nascido contra a permanência de fatores negativos. (...). Ainda em 1910 o grande Felipe Guerra citava as 22 cisternas e 25 cacimbas existentes em toda a cidade. E informava que estas últimas fornecem péssima água, intragável. (...). O rio orientava a fixação demográfica. A câmara Municipal de Apodi, certificando em 10 de julho de 1838, sobre os pretendidos limites pleiteados pelos mossoroenses para sua futura Freguesia, informava não haver habitações fora das margens do Rio Mossoró que é o mesmo Apodi" (CASCUDO, 1996).
}

Com relação ao que afirma Cascudo, da luta pela fixação da água no território mossoroense, podemos acrescentar o que descrevem Araújo et al. (2007).

"Com a intenção de evitar as enchentes que deixavam as vazantes submersas, a população, na década de oitenta (do século dezenove), resolveu canalizar o rio. O desvio fez com que o rio começasse a secar, e em 1905 o rio Mossoró parou de correr por trinta meses. Por isso, em 1917 o engenheiro Pedro Ciarlini foi chamado 
para construir obras contra as secas, entre as quais, as barragens no rio Mossoró. Foram construídas sete barragens espalhadas ao longo do rio, assim o rio não mais secava, mas a qualidade da água represada não atendia as condições de potabilidade. (...). Atualmente, o problema das enchentes foi sanado a partir do controle de vazão do rio por intermédio da Barragem de Santa Cruz que fica a montate do município. O sítio barrável está localizado sobre o rio Apodi, na Bacia do Apodi-Mossoró, no boqueirão denominado Santa Cruz, distante $18 \mathrm{~km}$ a montante da sede do município de Apodi/RN" (ARAÚJO et al., 2007).

Vemos nestes relatos, como a população da cidade tem uma longa convivência com este que é o maior rio do Estado do Rio Grande do Norte. Mas uma convivência que não vem sendo "pacífica" como nota-se na interferência para mudar o curso natural do rio (feita pela comunidade) ou pela decisão técnica de criar barragens para impedir a seca. Levando um meio lótico (rios) a ter características físico-químicas de um meio lêntico (lagos). Outro aspecto que tem que se levar em conta, quando se fala da relação dos moradores da cidade com o rio, é a poluição das águas, detectada por inúmeros trabalhos (ARAÚJO et al., 2007; CÂMARA et al., 2007; MARTINS et al., 2008a; MARTINS et al., 2008b).

Araújo et al. 2007 ao fazerem o monitoramento das águas do rio no período de 2005 a 2006, constatam que no referente a coliformes termotolerantes, a água próxima a barragem central apresenta um nível bem superior à classe $3^{4}$ apontada na resolução 357/05 do CONAMA que afirma que corpos de água com tal classificação devem ter no máximo 2500, enquanto os valores encontrados no rio chegam a surpreendentes 46867 coliformes termotolerantes por $100 \mathrm{ml}$.

Outro aspecto relevante é que em dois dos pontos em que se analisou a quantidade de oxigênio dissolvido, este é superior ao que se esperaria para águas tropicais, que deveria apresentar valores próximos a 8mg/L. A conclusão a que estes pesquisadores chegam é que devido ao acentuado processo de eutrofização, facilmente percebido pela presença de uma coloração verde da água, o limite máximo de saturação estava excedido em função da grande atividade das algas presentes. Há que se esclarecer que em algumas situações a eutrofização pode levar à diminuição da quantidade de oxigênio presente na água, principalmente quando leva ao surgimento de macrófitas (plantas aquáticas), o que não parece ser o caso dos locais onde foram coletadas as amostras deste estudo.

\footnotetext{
${ }^{4}$ Segundo a resolução 357/05 do CONAMA as águas classe 3 são aquelas que podem ser usadas para consumo humano depois de tratamento convencional ou avançado, que se prestam à pesca amadora, à irrigação de culturas cerealistas, forrageiras e arbóreas, à recreação de contato secundário e a dessecação de animais.
} 
Já Martins et al. (2007, 2008a, 2008b), apresentam estudos em 23 pontos ao longo de toda a extensão do Rio, desde a nascente até sua foz, concluindo que no rio desde a nascente até foz, os índices de dureza total, alcalinidade, sólidos totais e fosfato vêm aumentando em função da ação antropogênica ${ }^{5}$. Estes aumentos são mais evidentes em amostras coletadas nos maiores centros urbanos pelos quais o rio passa: Mossoró, Pau dos Ferros e Apodi. Outros autores como Câmara et al. (2007), destacam o papel que o crescimento demográfico, a atividade econômica e a urbanização do município exerceram sobre o rio.

Mas o grande consenso entre a maior parte dos autores e pesquisadores refere-se ao fato da maior fonte poluidora desse manancial serem os esgotos domésticos. Paiva (2005) afirma que somente na área destinada a preservação permanente da mata ciliar existem aproximadamente 14436 pessoas que despejam seus esgotos diretamente no leito do rio, sem nenhum tratamento prévio. Essa realidade é corroborada pelos resultados e pelas conclusões a que chegam Araújo (2007) e Martins (2008a e 2008b) ao determinarem os níveis de poluentes na água do rio entre 2006 a 2008.

\section{Considerações sobre o ensino de química}

A segunda etapa para a elaboração do terceiro módulo foi a escolha e teste de um experimento que pudesse estar relacionado com a realidade local e que permitisse a discussão contextualizada das interações CTSA. Essa escolha teve em consideração o que diversos autores discutem sobre a experimentação no ensino de ciências e da química (Hofstein, 2004 Hodson, 1994, Pereira, 2008). Principalmente as críticas que são feitas a forma tradicional com que esta é vista e praticada em todos os níveis de escolaridade.

Hofstein (2004) afirma que a experimentação tem exercido ao longo da história do ensino de química um papel central, constituindo-se no núcleo do currículo e sendo ao longo da década de 60 usada em diversas estratégias de ensino. Contudo, a ênfase dada ao papel da experimentação encontra-se na idéia do modelo de ensino por descoberta, ou como afirma Pereira (2008) ancorada em idéias positivistas. Contudo, como conclui este autor, as críticas

\footnotetext{
5 Martins et al, 2007 apresentam dados que confirmam o aumento nos valores dos parâmetros físico-químicos nas proximidades dos grandes centros urbanos pelos quais o rio passa: Mossoró, Apodi e Pau dos Ferros.
} 
feitas à experimentação são as mesmas feitas ao ensino tradicional, sendo a experimentação apenas uma atividade realizada segundo um modo tradicional. Considerando tais ponderações propomos uma atividade experimental com base na contextualização de problemas reais e sob uma perspectiva de construção social do conhecimento técnico científico.

\section{Quantidade de oxigênio dissolvido na água do rio Apodi-Mossoró}

Partindo da realidade local apresentada e tendo-se em vista o papel da experimentação no ensino de ciências, adaptou-se o experimento de determinação de oxigênio dissolvido na água, já apresentado e validado por Ferreira et al (2004), para se abordar a poluição das águas do Rio Apodi-Mossoró dentro do perímetro urbano da cidade de Mossoró. A seguir descrevemos as etapas da adaptação do experimento e seus resultados iniciais. 0 primeiro passo foi a coleta da água do rio em dois pontos distintos (Ponto 1, marcado pela eutrofização e ponto 2, uma ressurgência, onde a água apresenta-se cristalina - Figuras 3 e 4) onde amostras foram recolhidas em garrafas PET de $2 \mathrm{~L}$, às sete horas da manhã no primeiro ponto e às sete e quinze no segundo ponto. Em seguida, a água coletada foi filtrada com filtro de café previamente pesados para retirar as impurezas que pudessem induzir ao erro no momento da pesagem final da massa de oxigênio dissolvido.

Figura 3. Ponto de coleta 1.

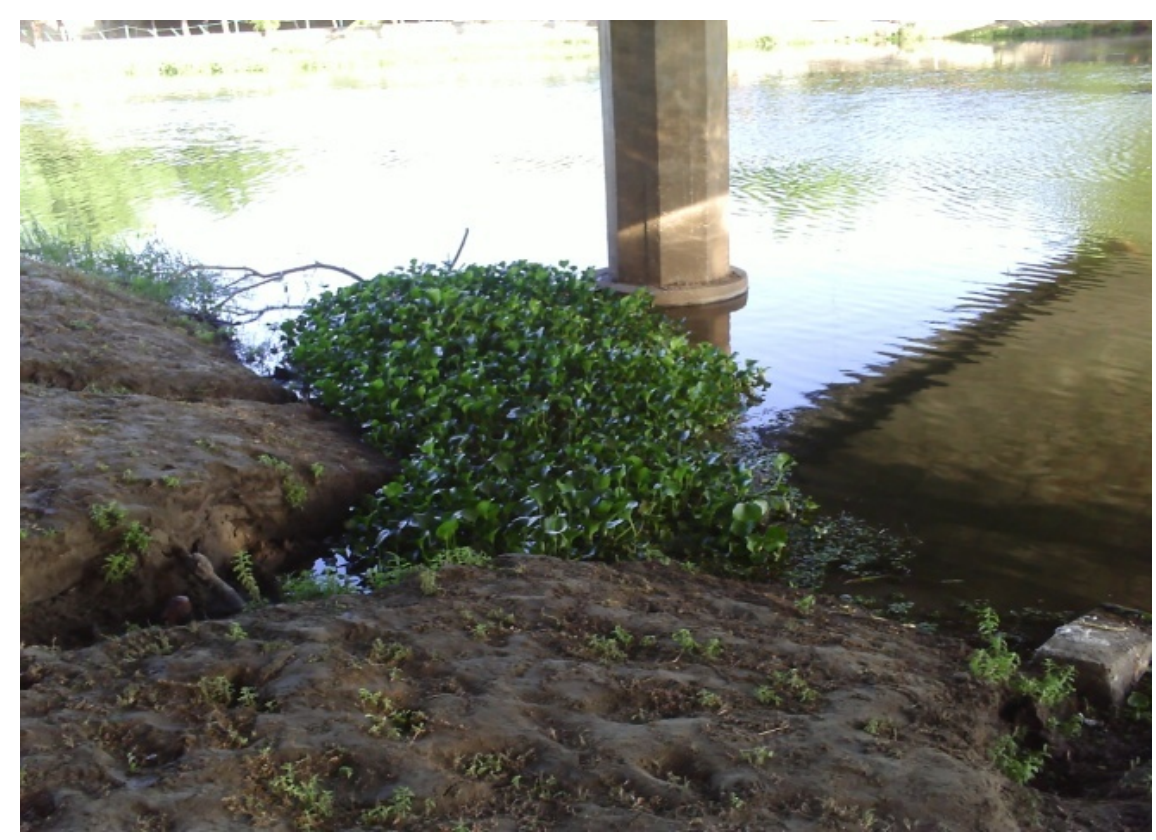




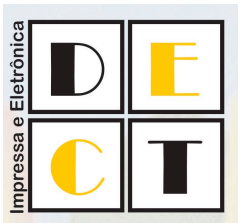

\section{Ensino de Ciências e Matemática Recurso didático de Química voltado ao Sertão Nordestino}

Figura 4. Ponto de coleta 2.

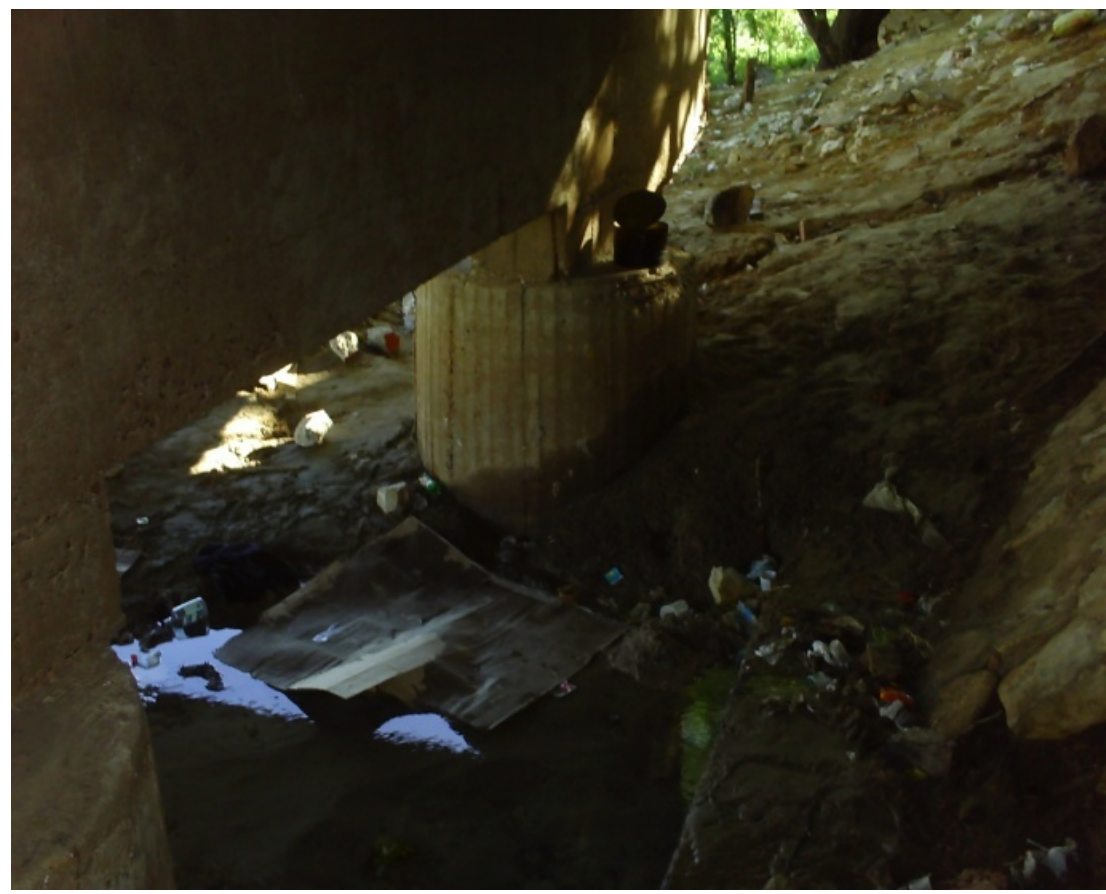

Para a realização do experimento pesou-se cerca de 1,5 gramas de palha de aço em uma balança analítica e com o auxílio de um bastão de vidro introduziu-se esta em uma garrafa PET, a qual foi preenchida com a amostra de água coletada no ponto 1 . 0 mesmo procedimento foi repetido para a mostra coletada no ponto 2, para uma amostra de água destilada e para duas amostras de água coletadas em torneiras das tubulações de distribuição. Cada uma das amostras de água teve seu pH medido em um pHmetro digital. Segundo Ferreira et al (2004) existem duas possibilidades de formação do óxido de ferro a partir da reação do oxigênio molecular presente na água e o ferro constituinte da palha de aço.

\section{Mecanismo 1:}

Redução:

$$
\mathrm{O}_{2}(\mathrm{~g})+2 \mathrm{H}_{2} \mathrm{O}(\mathrm{l})+4 \mathrm{e}^{-} \rightarrow 4 \mathrm{OH}^{-}(\mathrm{aq})
$$

Oxidação:

$$
\begin{aligned}
& \mathrm{Fe}(\mathrm{s}) \rightarrow \mathrm{Fe}^{2+}(\mathrm{aq})+2 \mathrm{e}^{-} \\
& \mathrm{Fe}^{2+}(\mathrm{aq}) \rightarrow \mathrm{Fe}^{3+}(\mathrm{aq})+\mathrm{e}^{-}
\end{aligned}
$$

Precipitação:

$$
\mathrm{Fe}^{3+}(\mathrm{aq})+3 \mathrm{OH}^{-}(\mathrm{aq}) \rightarrow \mathrm{Fe}(\mathrm{OH})_{3}(\mathrm{~s})
$$

Formação do óxido: 


$$
2 \mathrm{Fe}(\mathrm{OH})_{3}(\mathrm{~s})+(\mathrm{n}-3) \mathrm{H}_{2} \mathrm{O}(\mathrm{l}) \rightarrow \mathrm{Fe}_{2} \mathrm{O}_{3} \cdot \mathrm{nH}_{2} \mathrm{O}(\mathrm{s})
$$

\section{Mecanismo 2:}

Redução:

$$
\mathrm{O}_{2}(\mathrm{~g})+2 \mathrm{H}_{2} \mathrm{O}(\mathrm{l})+4 \mathrm{e}^{-} \rightarrow 4 \mathrm{OH}^{-}(\mathrm{aq})
$$

Oxidação:

$$
\mathrm{Fe}(\mathrm{s}) \rightarrow \mathrm{Fe}^{2+}(\mathrm{aq})+2 \mathrm{e}^{-}
$$

Precipitação:

$$
\mathrm{Fe}^{2+}(\mathrm{aq})+2 \mathrm{OH}^{-}(\mathrm{aq}) \rightarrow \mathrm{Fe}(\mathrm{OH})_{2}(\mathrm{~s})
$$

Oxidação adicional:

$$
\mathrm{Fe}(\mathrm{OH})_{2}(\mathrm{~s})+1 / 4 \mathrm{O}_{2}(\mathrm{~g})+1 / 2 \mathrm{H}_{2} \mathrm{O}(\mathrm{l}) \rightarrow \mathrm{Fe}(\mathrm{OH})_{3} \cdot \mathrm{nH}_{2} \mathrm{O}(\mathrm{s})
$$

Formação do óxido:

$$
2 \mathrm{Fe}(\mathrm{OH})_{3}(\mathrm{~s})+(\mathrm{n}-3) \mathrm{H}_{2} \mathrm{O}(\mathrm{l}) \rightarrow \mathrm{Fe}_{2} \mathrm{O}_{3} \cdot \mathrm{nH}_{2} \mathrm{O}(\mathrm{s})
$$

A partir das reações pode-se perceber a importância do tempo e do pH para a realização do experimento. Somente a partir de cinco dias todo o hidróxido de ferro precipitado terá sido convertido totalmente em óxido. E ainda, o pH básico favorece a formação do precipitado e, portanto, é imprescindível para bons resultados. Valores de $\mathrm{pH}$ ácidos dificultam a formação do óxido, podendo quando muito baixos impedir totalmente sua formação.

Desta forma, após cinco dias efetuou-se a filtração de cada uma das soluções das garrafas com filtro de café (previamente pesado) e pôs-se na estufa para secar e desidratar, uma vez que o óxido formado é hidratado. Pesou-se o papel de filtro depois de seco e foi feita a diferença para encontrar a quantidade de óxido de ferro presente. A diferença entre o valor de massa inicial (filtro de papel) e final (filtro de papel com óxido) é proporcional à quantidade de oxigênio dissolvido na água que reagiu com o ferro presente na esponja de aço. Os resultados são mostrados na tabela abaixo. 
Tabela 1. Valores de oxigênio dissolvido nas amostras analisadas.

\begin{tabular}{lccc}
\hline Amostra & $\begin{array}{c}\text { Massa de } \mathrm{Fe}_{2} \mathrm{O}_{3} \\
(\mathrm{~g})\end{array}$ & $\mathrm{pH}$ & $\begin{array}{c}\text { Concentração } \mathrm{O}_{2} \\
\text { (g/L) }\end{array}$ \\
\hline Ponto de coleta 1 & 0,7732 & 7,31 & 0,116 \\
Ponto de coleta2 & 0,1050 & 7,89 & 0,016 \\
Água destilada & 0,3086 & 7,02 & 0,046 \\
Água da tubulação 1 & 0,1019 & 7,98 & 0,015 \\
Água da tubulação 2 & 0,1018 & 7,98 & 0,015 \\
\hline
\end{tabular}

Diante dos dados obtidos a partir da busca de textos históricos e artigos científicos, bem como do experimento acima relatado chega-se a algumas considerações importantes:

- Os valores obtidos com o experimento para todas as amostras encontram-se significativamente acima dos valores máximos esperados para a água com saturação máxima de $\mathrm{O}_{2}$ a $25^{\circ} \mathrm{C}$ que seria de aproximadamente $0,008 \mathrm{~g} / \mathrm{L}$. O que nos indica que a desidratação do composto $\mathrm{Fe}_{2} \mathrm{O}_{3} \cdot \mathrm{n} \mathrm{H}_{2} \mathrm{O}$ não foi completa, um problema já relato por Ferreira et al (2004) em seu artigo original.

- Ainda que não se possa fazer considerações quantitativas exatas, o experimento traz a possibilidade de uma ótima discussão qualitativa, uma vez que a amostra 1, proveniente de um ponto eutrofizado do rio apresentou valores cerca de oito vezes maior que a água coletado no outro ponto ou na água distribuída na tubulação da UERN.

- A água da tubulação da $\mathrm{UERN}^{6}$ e da ressurgência apresentaram valores extremamente próximos o que é justificado por ambas serem águas provenientes do subsolo da cidade, de onde se depreendem que tenham características físico-químicas similares.

- O experimento não permite chegar à uma conclusão quantitativa sobre a qualidade de água em cada ponto em particular, contudo permite uma comparação entre amostras. Este aspecto pode ser útil para se trabalhar a discussão sobre elementos científicos de interesse na perspectiva CTSA, como a elaboração de hipóteses, discussão sobre a validade do método, a necessidade de outras metodologias e a incorporação de outros passos ao método adotado, entre outros.

${ }^{6}$ A água distribuída na tubulação da UERN provém de poço próprio e não muito distante do leito do Rio. 
- A execução desse experimento associada às discussões histórico-sociais e científicotecnológicas como brevemente esboçadas acima pode constituir-se em uma unidade didática para o ensino de química em uma perspectiva CTSA, com os seguintes passos:

\section{CONSIDERAÇÕES FINAIS}

O Rio Apodi-Mossoró constitui-se em bom exemplo de um problema real das cidades de Pau dos Ferros, Apodi e Mossoró, e sua história demonstra como a ação tecnológica e humana, representou e ainda representa um impacto ambiental. 0 estudo deste problema requer o conhecimento químico para sua compreensão, e assim torna-o um tema interessante para a formação dos licenciandos em química da região numa perspectiva CTSA.

Outro aspecto interessante a se levar em consideração é que esta prática põe de releve a limitação de uma única ciência para explicar aspectos complexos da realidade ambiental. Sendo assim, para o bom entendimento dos parâmetros utilizados e o porquê do aumento da quantidade de oxigênio dissolvida na água, se fazem necessários conhecimentos ainda que básicos sobre ciências biológicas (referente ao crescimento de plantas aquáticas e microorganismos) e geografia. Desta forma, constitui-se em uma atividade transdisciplinar o que propicia uma compreensão da necessidade da comunicação entre as áreas do conhecimento.

Ressalta-se que a mesma unidade aqui proposta poderia ser desenvolvida em outras localidades nas quais a poluição das águas de mananciais seja provocada pelo despejo de matéria orgânica. $\mathrm{O}$ recurso didático, elaborado como suporte à unidade e composto por três módulos cumpriu, a nosso ver, os objetivos iniciais do projeto que eram:

- Discutir as relações CTSA na licenciatura em química;

- Propor uma atividade baseada no contexto local para a discussão de temas CTSA;

- Disponibilizar uma atividade reprodutível em escolas de ensino médio.

- Contudo, uma avaliação pré-eliminar demonstrou que o mesmo necessita de reformulações com o intuito de adequar a linguagem utilizada ao vocabulário dos estudantes. 


\section{Ensino de Ciências e Matemática \\ Recurso didático de Química voltado ao Sertão Nordestino}

\section{REFERÊNCIAS}

ARAÚJO, V. S. de. SANTOS, J. P. dos. ARAÚJO, A. L. C. Monitoramento das águas do rio Mossoró/RN, no período de abril/2005 a julho/2006, Holos, vol. 23, p. 4-41. 2007.

CÂMARA, J. H. C., Souza, F. das C. S., Pinheiro, K. L. C. B., Barreto, S. L., Alves, G. S., II (2007). Congresso de Pesquisa e Inovação da Rede Norte Nordeste de Educação Tecnológica João Pessoa - PB.

CASCUDO, L. da C., (1996). Notas e documentos para a história de Mossoró, Coleção Mossoroense Mossoró: ETFRN/Uned Mossoró / Petrobrás SA.

CEREZO, J. A. L. (1998) Ciencia, Tecnología y Sociedad: el estado de la cuestión en Europa y Estados Unidos, Revista Iberoamericana de Educación, 18< http://www.rieoei.org/oeivirt/rie18a02.htm>.

UERN. Departamento de Química. Projeto Político Pedagógico do Curso de Licenciatura em Química. Mossoró: UERN. 2008.

Ferreira, L. H., Abreu, D. G. de, Iamamoto, Y. \& Andrade, J. F. de, (2004) Determinação simples de oxigênio dissolvido na água, Química nova na escola. 1 (19), 32-35.

GARCÍA, M. I. G. López, CEREZO, J. A. Lujan. LÓPEZ, J. L. Ciencia, tecnología y sociedad: una introducción al estudio social de la ciencia y la tecnología. Madri: Tecnos. 1996.

HODSON, D. Hacia um enfoque más crítico del trabajo de laboratório, Enseñanza de las ciências, 3 (12) 299-313. 1994.

HOFSTEIN, A. The laboratory in chemistry education: thirty years of experience with developments, implementation, and research, Chemistry Education: research and practice, 3 (5) 247-264. 2004.

IBGE. Instituto Brasileiro de Geografia e Estatística. Disponível em www.ibge.gov.br, acessada em 14/05/2009. 2009.

MANASSERO, M. A. Más. VÁSQUEZ, A. Alonso. Atitudes e creencias de los estudiantes relacionadas com CTS in Membiela, P. Enseñanza de las ciencias desde la perspectiva Ciencia-Tecnología-Sociedad: Formación científica para la ciudadanía. Madrid: Narcea. 2001.

MARTINS, D. F. F. SOUZA, R. B. OLIVEIRA, T. M. B. F. SOUZA, L. D. CASTRO, S. S. L. Qualidade físicoquímica das águas da bacia do rio Apodi/Mossoró: I- Variabilidade espacial. Anais do I congresso norte-nordeste de química, Natal. 2007.

MARTINS, D. F. F. SOUZA, R. B. OLIVEIRA, T. M. B. F. SOUZA, L. D. CASTRO, S. S. L. Qualidade físicoquímica das águas da bacia do Rio Apodi/Mossoró: I- Variabilidade Espacial. Química no Brasil, 1 (2), 61-74. 2008.

MARTINS, D. F. F. CASTRO, S. S. L. Qualidade físico-química das águas da bacia do Rio Apodi/Mossoró: II- Variabilidade Temporal. Química no Brasil, 2 (2), 9-23. 2008.

MEMBIELA, P. Uma revisión del movimiento CTS em La enseñanza de las Ciencias. 2001. In: MARTINS, D. F. F. (org.). Enseñanza de las Ciências desde la perspectiva Ciência-Tecnología-Sociedad: Formación científica para la ciudadanía. Madrid: Nancea. 2001.

NUNES, A. O. NUNES, A. O. HUSSEIN, F. G. S. OLIVEIRA, O. A. AMARAL, J. A. DANTAS, J. M. As atitudes de estudantes da rede brasileira de educação tecnológica sobre as relações entre Ciência-Tecnologia Sociedade- Ambiente (CTSA). Enseñanza de las Ciencias, v. Extra, p. 2589-2594, 2013.

NUNES, Albino Oliveira. DANTAS, J. M. As relações ciência tecnologia sociedade-ambiente (CTSA) e as atitudes dos licenciandos em química. Educación Química, v. 23, p. 85-90, 2012. 
SUTIL, N. CTS E CTSA em periódicos nacionais em Ensino De Ciências/Física (2000-2007): Aspectos Epistemológicos e Sociológicos, Anais do XI Encontro de Pesquisa em Ensino de Física Curitiba. 2008.

PAIVA, C. Área de preservação do Rio Mossoró está ocupada. Disponível em: http://www.mp.rn.gov.br/imprensa.asp?cod=11. Acesso em 20 do março de 2013. 2009.

PEREIRA, C. L. N. A história e a experimentação no ensino de química orgânica, Brasília: UNB (Dissertação de Mestrado). 2008.

UERN. Disponível no site www.uern.br, acessado em 15/05/2009. 2009.

TOMAZELlO, M. G. C. O Movimento Ciência, Tecnologia - Sociedade - Ambiente na Educação em Ciências, Anais do I Seminário Internacional de Ciência, Tecnologia e Ambiente, Cascavel. 2009. 